Article

\title{
Insight to the Influence of Ti Addition on the Strain-Induced Martensitic Transformation in a High (about 7 wt.\%) Mn Stainless Steel
}

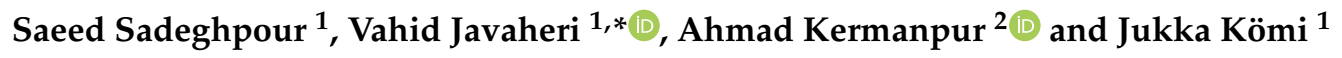 \\ 1 Centre for Advanced Steels Research, University of Oulu, 90014 Oulu, Finland; \\ saeed.sadeghpour@oulu.fi (S.S.); Jukka.Komi@oulu.fi (J.K.) \\ 2 Department of Materials Engineering, Isfahan University of Technology, Isfahan 8415683111, Iran; \\ ahmad_k@iut.ac.ir \\ * Correspondence: vahid.javaheri@oulu.fi
}

Received: 6 April 2020; Accepted: 24 April 2020; Published: 27 April 2020

\begin{abstract}
The kinetics of strain-induced martensite (SIM) formation in a Ti-bearing 201L stainless steel were evaluated and compared to the existing results of two conventional stainless steel grades; i.e., 201L and 304L AISI. The effects of strain rate and rolling pass reduction on the kinetics of SIM formation during cold rolling were investigated. The Ti-microalloying was found to be intensifying the transformation due to lowering the stacking fault energy. It was seen that decreasing the rolling pass reduction strongly affected the variation of SIM volume fraction. Furthermore, a close correlation between the hardness and strain-induced transformation was found arising from microstructural evolution during the cold rolling process. Three stages in the hardening behavior were detected associated with lath-type martensite formation, transition stage of martensite laths break up and formation of dislocation-cell-type martensite.
\end{abstract}

Keywords: metastable austenite; Ti-bearing stainless steel; strain-induced martensitic transformation

\section{Introduction}

Metastable austenitic stainless steels (ASSs) which generally have a low stacking fault energy (SFE), are highly susceptible to strain-induced martensitic transformation. The formation of strain-induced martensite (SIM) is closely related to the intersecting of shear bands that form during deformation when stacking faults overlap on austenite $\{111\}$ planes [1]. This phase transformation may have two martensite products: paramagnetic $\varepsilon$-martensite phase with a hexagonal close-packed (hcp) crystal structure and ferromagnetic $\alpha^{\prime}$-martensite phase with a body centered cubic (bcc) structure.

As regards martensite formation, three transformation sequences are suggested: $\gamma \rightarrow \varepsilon, \gamma \rightarrow \alpha^{\prime}$ and $\gamma \rightarrow \varepsilon \rightarrow \alpha^{\prime}$ [1]. Several factors have been reported as the main parameters influencing the formation of SIM in ASSs, such as deformation temperature, strain, strain rate, stress state and grain size [2-5]. In addition to above mentioned, steel chemical composition has a major effect on martensitic transformation. The effect of steel chemistry can be explained in terms of the chemical free energy difference between austenite $(\gamma)$ and $\alpha^{\prime}$-martensite phases which acts as the chemical driving force. It has been suggested [6] that the stability of austenite against SIM formation is determined mainly by SFE which controls the formation of shear bands and thus the formation of nucleation sites for the SIM. It is also reported that the SFE is strongly dependent on the composition $[7,8]$ and temperature [9]. Therefore, the compositional dependence of the austenite stability can be explained by variation in SFE caused by the variation in composition.

In recent years, stainless steels containing high Mn content (e.g., 200 series) have been considered as potential substitutes for the common 300 series ASSs due to the partial replacement of costly Ni 
by Mn [10]. Thus, many research interests have been aroused for investigation of SIM formation in 200 series ASSs [11-14]. Nevertheless, the effects of microalloying, strain rate and stress state on the kinetics of SIM formation in 200 series have not been intensively and systematically investigated yet.

The aim of this work is to study the strain-induced martensitic transformation behavior of a Ti-microalloyed 201L stainless steel. The influences of Ti addition on the kinetics of SIM formation and their implications for strain rate were investigated. Additionally, the effect of strain increase on the kinetics of SIM formation was studied for the first time. Besides, two commonly investigated stainless steel grades, i.e., 304L and 201L, were selected as the reference materials. The results for the studied material were compared with those of the reference materials from the literature when the data were available. The literature results were mainly extracted from $[15,16]$.

\section{Materials and Experimental Procedures}

The composition of the steel used in this study along with the nominal chemical compositions of AISI 304L and AISI 201L (literature reference materials) are listed in Table 1. Initially, the solution annealing was carried out at $1200{ }^{\circ} \mathrm{C}$ for $8 \mathrm{~h}$ followed by water quenching. Then, the annealed plate was slightly ground to remove any surface scale. Afterward, the multi-pass unidirectional cold rolling was carried out to make different thickness reductions from $0 \%$ to $90 \%$ with different strain rates of 0.1 , 0.5 and $1.5 \mathrm{~s}^{-1}$ at room temperature. Specimens were cold rolled with uniform thickness reductions of 0.2 and $0.05 \mathrm{~mm}$ per pass in a same rolling direction.

Table 1. Chemical compositions (in wt.\%) of Ti-bearing 201L, 201L and 304L stainless steels.

\begin{tabular}{cccccccc}
\hline Steel & C & Mn & Cr & Ni & Ti & Si & Fe \\
\hline 201L + Ti (studied material) & 0.025 & 7.20 & 16.73 & 4.30 & 0.12 & 0.25 & Bal. \\
201L (literature reference material) & 0.027 & 5.91 & 16.20 & 3.88 & - & 0.51 & Bal. \\
304L (literature reference material) & 0.027 & 1.58 & 18.20 & 8.22 & - & 0.43 & Bal. \\
\hline
\end{tabular}

To prepare the metallography samples, the common preparation technique followed by subsequent electro-polishing in an electrolytic bath of $200 \mathrm{~mL} \mathrm{HClO} 4+800 \mathrm{~mL}$ ethanol was performed. Then, specimens were electrolytically etched in nitric acid $\left(\mathrm{HNO}_{3}\right)$ solution to reveal the microstructure. The microstructures were investigated using a light optical microscope "Olympus." X-ray diffraction (XRD) analysis was carried out for phase identification using a Philips X'pert diffractometer with $\mathrm{Cu}$ $\mathrm{K} \alpha$ radiation at room temperature in the range of $30^{\circ}-100^{\circ}$. The volume fraction of SIM was measured using a ferritescope (Fischer MP30E). The ferritescope data were converted to SIM volume fraction by multiplying with a correction factor of 1.7, according to [17]. All the specimens were electropolished before each test in order to minimize errors in determining SIM volume fraction due to martensite formation during mechanical sample preparation.

The hardness of specimens was measured by the Vickers hardness (HV) method by applying $10 \mathrm{kgf}$ load. Ten measurements were obtained from each sample, and an average value was reported as the result.

\section{Results and Discussion}

Figure 1 shows the microstructures of as-received, 10\%, 15\% and 20\% cold rolled samples. The as-received microstructure consisted of equiaxed austenitic grains (with an average grain size of $30 \mu \mathrm{m}$ ) with typical fraction of delta ferrite on the grain boundaries and triple junctions (dark regions Figure 1a). After 10\% (cold) thickness reduction, several martensitic variants were observed inside the grains. As expected, the amount of martensite (dark regions in Figure 1b-d) is increased with increasing the reduction percentage during cold rolling. Through the sample preparation, we attempted to apply as little as possible force to avoid any extra martensite formation, which of course affected the quality of micrographs. 

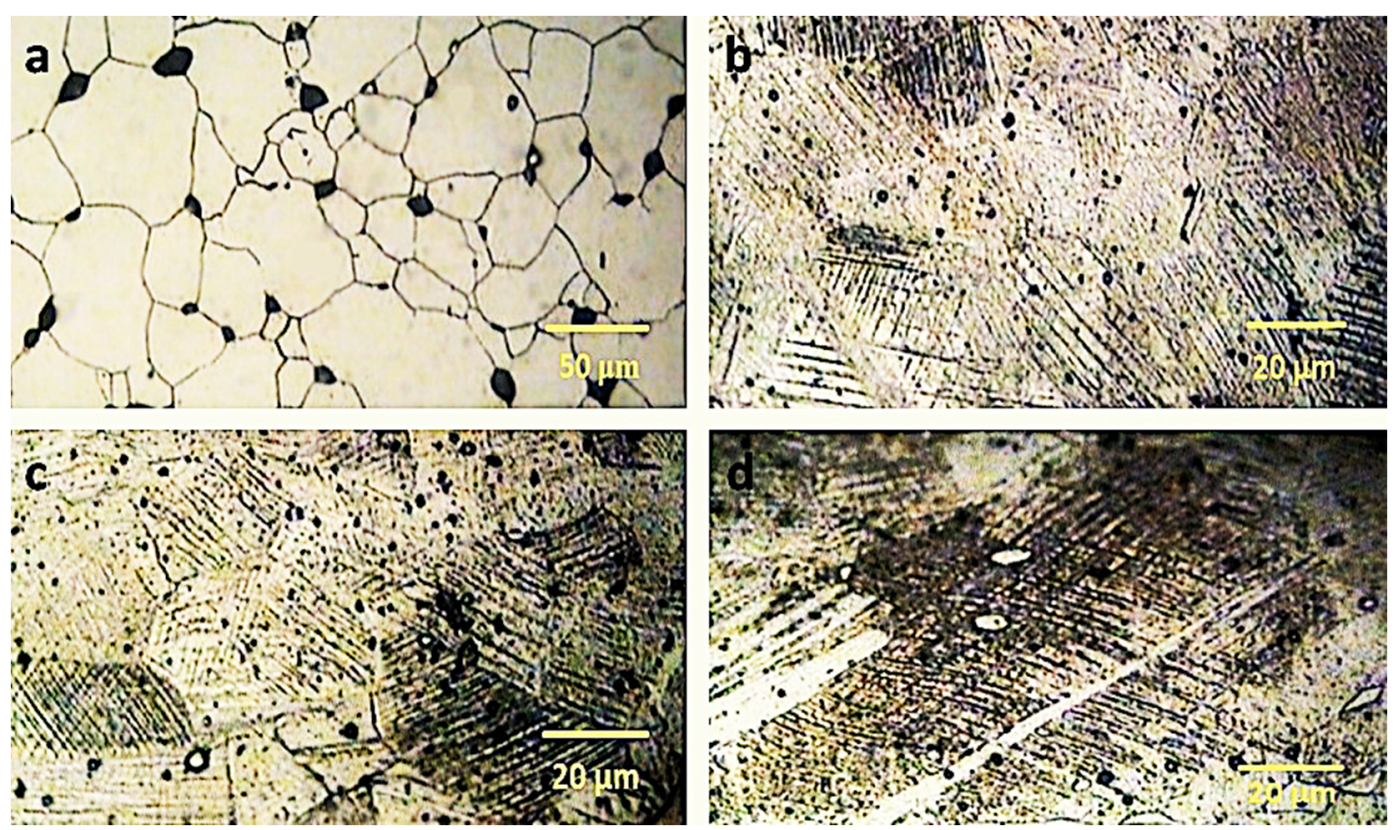

Figure 1. Light optical micrographs of Ti-bearing 201L steel in (a) non-deformed state and after (b) $10 \%$ (c) $15 \%$ and (d) $20 \%$ thickness reductions.

The XRD patterns of the as-received and 5\%, 25\%, 35\% and 90\% cold-rolled specimens are presented in Figure 2. The microstructure of the $5 \%$ cold-rolled sample consisted of $\gamma$-austenite, $\alpha^{\prime}$-martensite and $\varepsilon$-martensite phases.

Figure 2 shows only the presence of austenite in the XRD pattern of as-received sample. Thus, it can be concluded that martensite phases are generated during the deformation process. As can be seen, weak $\varepsilon(10 \overline{1} 0)$ and $\varepsilon(\overline{1} 011)$ reflections are detected from the XRD pattern of the $5 \%$ cold-rolled specimen, confirming $\varepsilon$-martensite formation in the early stages of deformation. When increasing the strain further, $\gamma$ and $\varepsilon$ reflections disappear, while the intensity of $\alpha^{\prime}$ reflection increases. As mentioned before, strain-induced martensitic transformation can occur through the three commonly observed $\gamma \rightarrow \varepsilon, \gamma \rightarrow \varepsilon \rightarrow \alpha^{\prime}$ and $\gamma \rightarrow \alpha^{\prime}$. The present results show that the austenite $(\gamma)$ transforms to $\alpha^{\prime}$-martensite through the $\gamma \rightarrow \varepsilon \rightarrow \alpha^{\prime}$ sequence. This sequence has not been observed in conventional 304L [4] and 201L [11] steels, except at low deformation temperatures, and consequently low SFE. According to Talonen and Hanninen [6], the $\varepsilon$-martensite forms in steels with low SFE; the transformation sequence of the present Ti-bearing steel is also attributed to its low SFE, as will be described later. In this transformation sequence, $\varepsilon$-martensite acts as the precursor phase of $\alpha^{\prime}[18,19]$. Olson and Cohen [20] suggested that the shear produced by two intersecting $\varepsilon$-martensite bands caused a distortion shifting of original austenite lattice to the final $\alpha^{\prime}$-martensite structure. The $\alpha^{\prime}$-martensite nucleates in the intersection of the $\varepsilon$-martensite bands [21,22]; or in the intersection of the slip bands, grain boundaries or twin boundaries and $\varepsilon$-martensite bands [4]. It is seen that the amount of austenite and $\varepsilon$-martensite decreases with increasing thickness reduction owing to gradual transformation of $\gamma \rightarrow \varepsilon$ and then $\varepsilon \rightarrow \alpha^{\prime}$, so that after $35 \%$ thickness reduction, the $\alpha^{\prime}$ reflections are observed solely. With increasing the cold reduction to $90 \%, \alpha^{\prime}$ peaks are broadened, because of very fine martensite structure and an extreme increase in crystal defects.

Figure 3a illustrates the calculated volume fraction of $\operatorname{SIM}\left(f^{\alpha^{\prime}}\right)$ as a function of true strain $(\varepsilon)$ in comparison with 201L [15] and 304L [16] ASSs. As can be seen, martensite formation follows a curve with sigmoidal shape so that it rapidly increases and becomes saturated at a specific $\operatorname{strain}\left(\varepsilon_{\mathrm{s}}\right) \cdot \varepsilon_{\mathrm{s}}$ plays an important role in attaining nano/ultrafine-grained structure in subsequent reversion treatment of the cold-rolled ASSs $[15,23,24]$. The volume fraction and grain refinement of reverted austenite are also depended upon the $\varepsilon_{\mathrm{s}}$. 


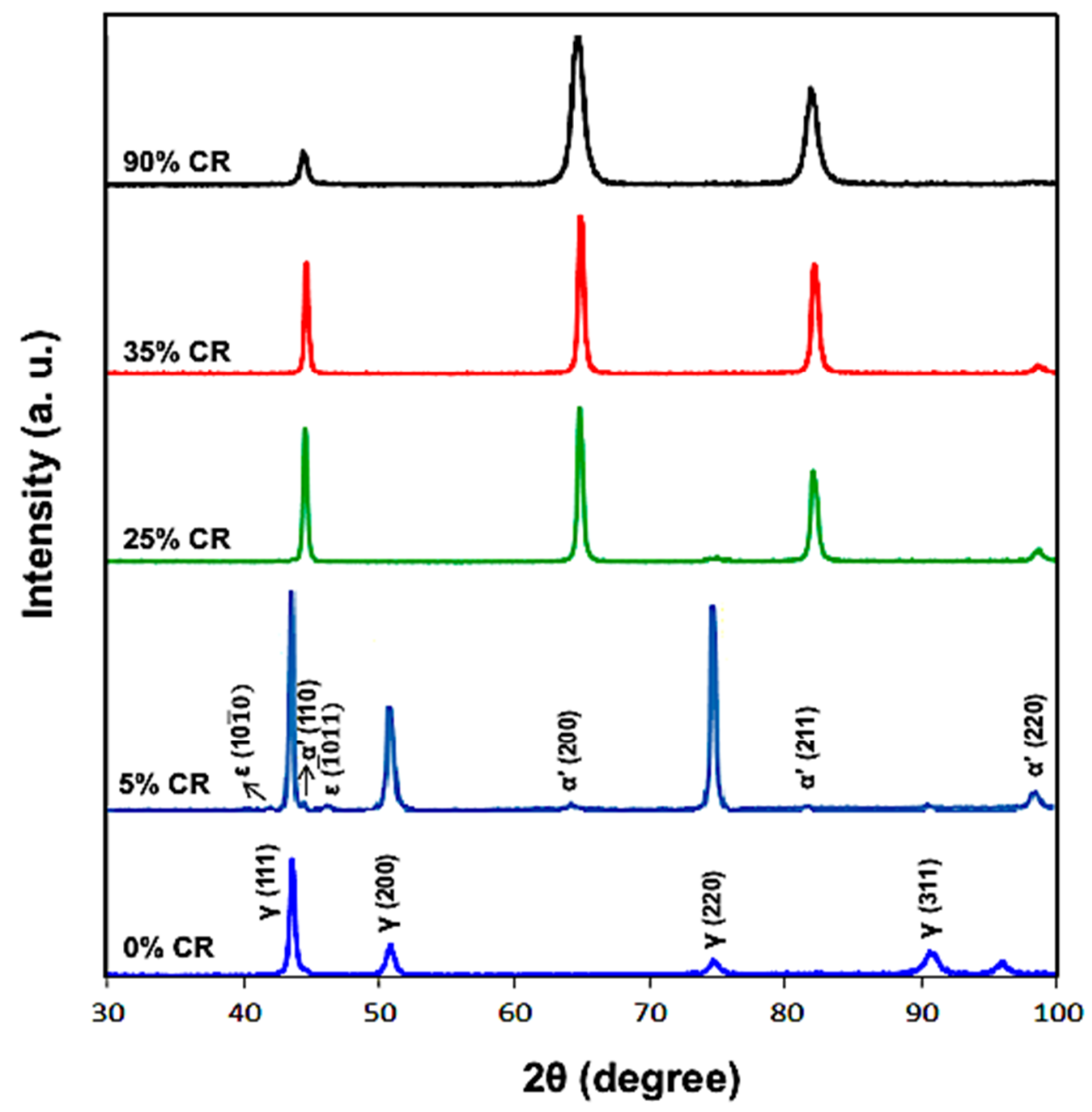

Figure 2. X-ray diffraction patterns of the cold rolled Ti-bearing 201L steel after different thickness reductions.

Decreasing $\varepsilon_{\mathrm{S}}$ assists the grain refinement by providing large number of crystal defects and numerous nucleation sites for austenite during the reverse treatment [24]. The $\varepsilon_{\mathrm{S}}$ values are listed in Table 2 for different steels. According to Figure 3 and Table 2, both Ti-bearing 201L and 201L steels show lower $\varepsilon_{\mathrm{S}}$ than $304 \mathrm{~L}$ steel. The major austenite stabilizer element in the 200 series of ASSs is Mn instead of $\mathrm{Ni}$, and it has been reported that the 200 series is more susceptible to SIM formation due to lower SFE [12]. Moreover, the Ti-bearing 201L steel has lower $\varepsilon_{\mathrm{S}}$ than that of 201L.

Table 2. The saturation strain $\left(\varepsilon_{s}\right)$ and Olson-Cohen parameters obtained for 304L, 201L and 201L + Ti steels.

\begin{tabular}{cccc}
\hline Parameter & 304L & 201L & 201L + Ti \\
\hline$\varepsilon_{\mathrm{S}}$ & 1.6 & 0.6 & 0.42 \\
$\alpha$ & 3.3 & 4.8 & 4.90 \\
$\beta$ & 3.6 & 6.1 & 7.80 \\
\hline
\end{tabular}



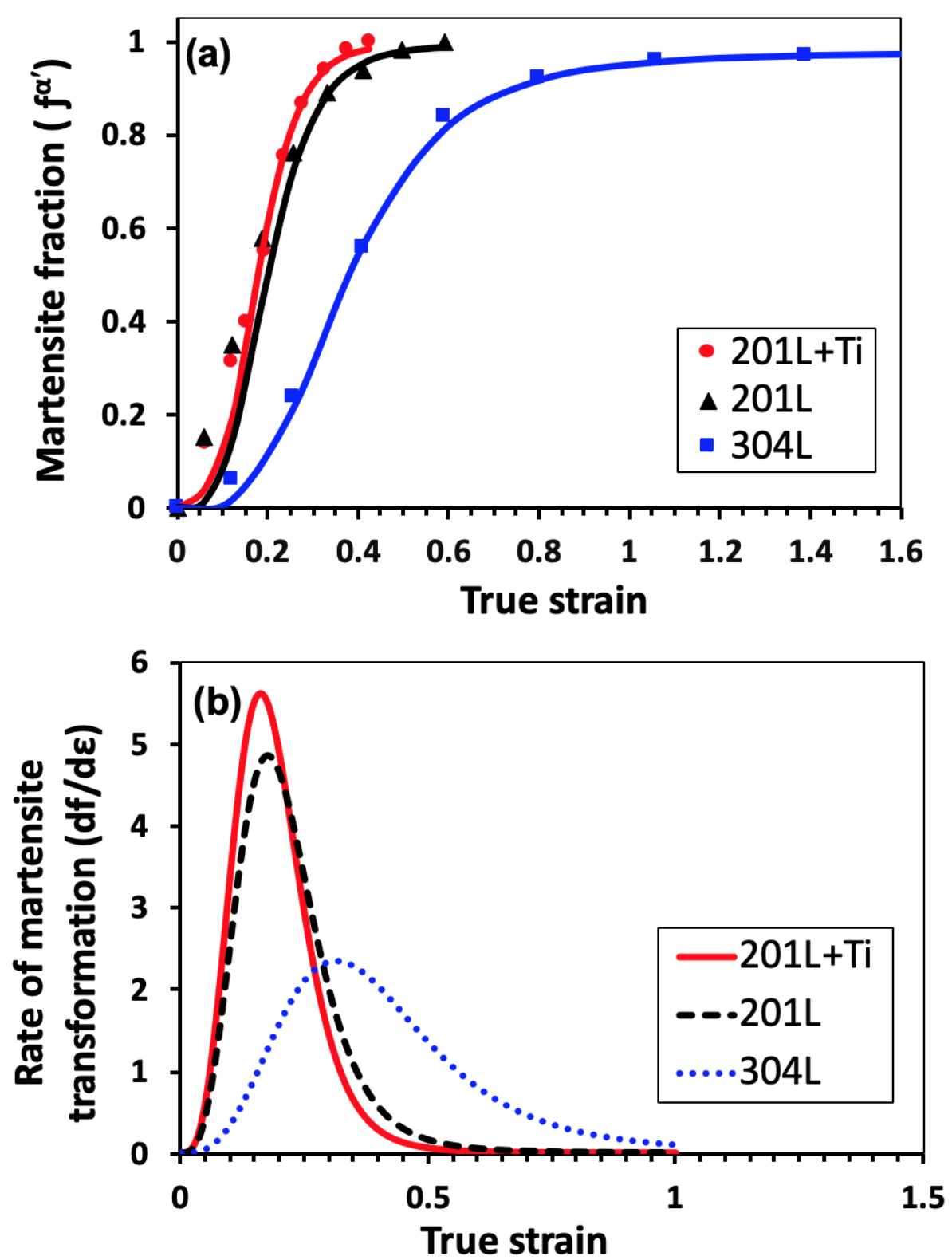

Figure 3. (a) Volume fraction of $\operatorname{SIM}\left(f^{\alpha^{\prime}}\right)$ as a function of true strain for $304 \mathrm{~L}, 201 \mathrm{~L}$ and $201 \mathrm{~L}+\mathrm{Ti}$ steels cold rolled at room temperature. (b) Corresponding curves of the rate of martensite formation $\left(\mathrm{d} f^{\alpha^{\prime}} / \mathrm{d} \varepsilon\right)$ as a function of true strain.

It can be attributed to the presence of Ti affecting the stability of austenite. It has been reported that the addition of Ti to the 316 steel decreases its SFE [25]. In addition, precipitation of Ti-rich phases may affect the austenite stability. For example, during solution annealing at $1200^{\circ} \mathrm{C}$, the TiC carbides formed during solidification may dissolve incompletely and remain in the matrix. Therefore, the retained $\mathrm{TiC}$ may lead to the depletion of $\mathrm{C}$ in the austenite, resulting in a lower SFE and consequently an enhanced susceptibility to SIM formation. The thermodynamic calculation (Figure 4) shows that, for the studied composition, Ti solubility temperature is about $1160{ }^{\circ} \mathrm{C}$, which is below the solution treatment temperature; however, a slight level of segregation during solidification, which is very common in this alloy due to high amounts of silicon, manganese and alloying elements, will increase Ti solubility temperature and possibility of undissolved $\mathrm{TiC}$ during the solution treatment. 


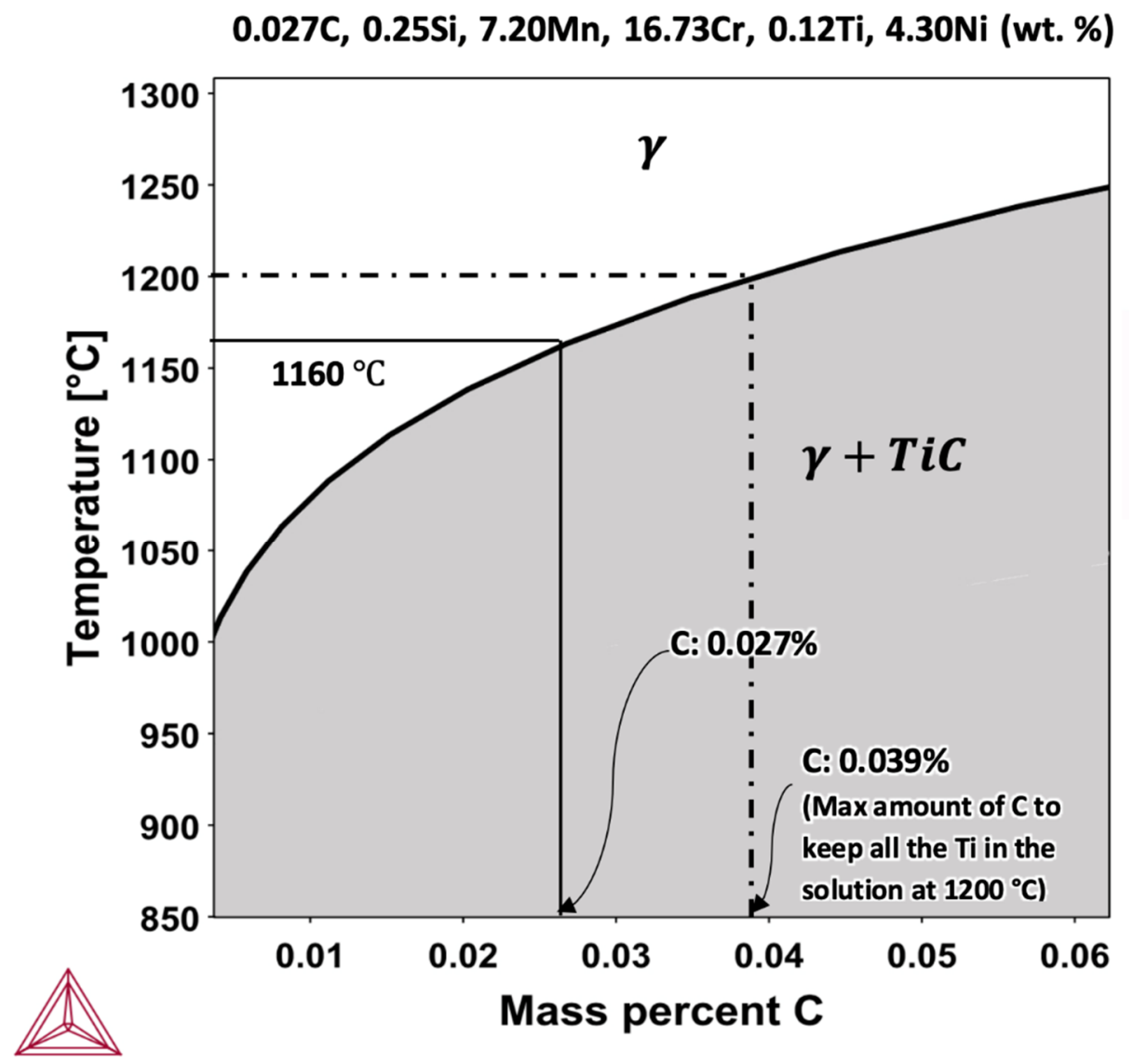

Figure 4. Phase diagram showing Ti solubility in austenite for the studied steel composition (calculated using Thermo-Calc).

The volume fraction data were analyzed using the Olson and Cohen model [20] which has been extensively used to estimate the kinetics of SIM formation during rolling. They suggested the following equation relating the volume fraction of $\alpha^{\prime}$-martensite, $f^{\alpha^{\prime}}$, to strain, $\varepsilon$ :

$$
f^{\alpha^{\prime}}=1-\exp \left\{-\beta[1-\exp (-\alpha \varepsilon)]^{\mathrm{n}}\right\},
$$

where $\varepsilon$ is the true strain, $\alpha$ and $\beta$ are temperature dependent parameters and $n$ is a constant experimental exponent equal to 4.5 . The $\alpha$ parameter defining the shear-band formation, is mainly dependent on the SFE of steel. Since the SFE depends on temperature, the $\alpha$ parameter is also temperature dependent. The $\beta$ parameter is related to the probability of the nucleation of $\alpha^{\prime}$-martensite at a shear band intersection. The temperature dependence of $\beta$ parameter is due to the fact that the chemical driving force of $\alpha^{\prime}$-martensite formation depends on temperature as well [26]. Figure 3a shows the fitting results of Equation (1) for the experimental data for 304L, 201L and 201L + Ti steels. The considered $\alpha$ and $\beta$ parameters are listed in Table 2. It can be seen that the value of $\alpha$ is higher for $201 \mathrm{~L}+\mathrm{Ti}$ steel than those of the 201L and 304L steels. Knowing that the $\alpha$ parameter determines the rate of shear band formation and is a function of SFE of steel, the higher value of $\alpha$ could be related to the lower SFE seen in the 201L + Ti as compared to 201L and 304L steels arising from the presence of Ti and higher content of $\mathrm{Mn}$. The $\beta$ parameter was also found to decrease with increasing SFE due to the decrease in the probability of the nucleation of $\alpha^{\prime}$-martensite.

Figure $3 \mathrm{~b}$ shows the first derivatives $\left(\mathrm{d} f^{\alpha^{\prime}} / \mathrm{d} \varepsilon\right.$ ) of the fitted curves given in Figure $3 \mathrm{a}$, representing the rate of SIM transformation. The 201L + Ti steel shows a higher transformation rate and the maximum rate, which is obtained when the inflection point of the curve is reached at a lower strain. This higher transformation rate that becomes sharper with the progress of deformation, has also been 
reported by Tavares [12] and could be a consequence of the lower SFE of 201L + Ti as compared to 201L and 304L steels. Figure 5a shows the influence of strain rate on the volume fraction of SIM as a function of true strain for 201L + Ti steel. By comparing the results for different strain rates, it is observable that the SIM formation is suppressed with increasing strain rate and the $\varepsilon_{\mathrm{s}}$ values are shifted to higher strain values. It has been described in terms of the adiabatic heating lowering the $\Delta G^{\gamma \rightarrow \alpha}[3,27,28]$. However, Talonen and Hanninen [6] showed that the temperature dependence of the SFE is the main reason for the suppression of SIM formation at high strain rates. This can be attributed to the local variation of stacking fault energy of material due to adiabatic heating. At a higher strain rate, the heat generated during deformation leads to an increase in temperature during cold rolling. Since ASSs have a low thermal conductivity, this local raise in temperature is higher when the strain rate is increased. Therefore, the variation in the SFE during high strain rate may significantly suppress the formation of shear bands and consequently SIM formation. The present result is in accordance with the findings of Talonen and Hanninen. The curves resulted from the fitting of Equation (1) are shown in Figure 5a, and the parameters of Equation (1) are listed for them in Table 3. It is shown that $\alpha$ parameter shows a light decrease with increasing the strain rate. This is in contrast with the assumption made by Talonen et al. [29], who assumed that the $\alpha$ parameter is independent of adiabatic heating, since the increase in temperature has a minor effect on the SFE. However, the $\beta$ parameter was found to decrease with increasing strain rate, which is in agreement with Talonen et al. [29]. This could be the consequence of the adiabatic heating which reduces the chemical driving force of $\gamma \rightarrow \alpha^{\prime}$ transformation.

Table 3. Values for $\alpha$ and $\beta$ parameters determined from the fitting of Olson-Cohen equation to 201L + Ti steel at different rolling strain rates.

\begin{tabular}{cccc}
\hline Parameter & $\mathbf{0 . 1} \mathbf{~ s}^{\mathbf{- 1}}$ & $\mathbf{0 . 5} \mathbf{~ s}^{\mathbf{1}}$ & $\mathbf{1 . 5} \mathbf{~ s}^{\mathbf{1}}$ \\
\hline$\alpha$ & 5.2 & 4.9 & 4.8 \\
$\beta$ & 11 & 7.8 & 6.5 \\
\hline
\end{tabular}

The rate of SIM formation at different strain rates is shown in Figure 5b. By increasing the strain rate, the rate of SIM transformation decreases, and the maximum value shifts to a higher strain value. The values of strain related to the maximum transformation rate for the specimen rolled at the strain rates of $0.1,0.5$ and $1.5 \mathrm{~s}^{-1}$ are $0.14,0.16$ and 0.18 , respectively. As mentioned before, at high strain rates the adiabatic heating increases the austenite stability, restricting the transformation.

An interesting feature in Figures 3 and 5 is that the maximum value of the $\gamma \rightarrow \alpha^{\prime}$ transformation rate corresponds in all cases to the approximately same volume fraction of SIM. It means that irrespective of the chemical composition and strain rate, when the volume fraction of SIM reaches a critical value of about 30 pct., the transformation rate starts to decrease. This phenomenon that has also been reported by Talonen at al. [29] can be explained in terms of the percolation theory. For site percolation, i.e., the formation of infinite clusters of $\alpha^{\prime}$-martensite phase, the percolation threshold has been shown to be 0.3116 [30]. After this critical fraction, it can be assumed that $\alpha^{\prime}$-martensite forms a continuous network through the material and the formation of martensite becomes more difficult.

In order to describe the influence of thickness reduction per pass on the formation of SIM, cold rolling was performed at the same strain rate $\left(0.5 \mathrm{~s}^{-1}\right)$ and two thickness reductions of $0.2 \mathrm{~mm}$ and $0.05 \mathrm{~mm}$ per pass. Figure 6 shows the volume fraction of SIM as a function of true strain. The lower pass reduction behaved distinctly different from the higher pass reduction. However, the saturation value $\left(\varepsilon_{S}\right)$ is approximately equal for the 0.2 and $0.05 \mathrm{~mm}$ pass reductions. This is contrary to the results found by Somani et al. [31] who reported that a higher pass reduction results in lower SIM fractions for the same degree of deformation, due to intense adiabatic heating. According to this, for a low pass reduction such as $0.05 \mathrm{~mm}$ per pass, a higher fraction of martensite is expected to form, but the present results show an opposite behavior. It should be mentioned here that in comparison with Somani et al. [31] both of the applied pass reductions in the present work are so low that the effect of adiabatic heating may not be determinant. In the other words, in contrast to high pass reductions 
in which the adiabatic heating is significant, at low pass reductions, other factors may delineate the transformation kinetics.
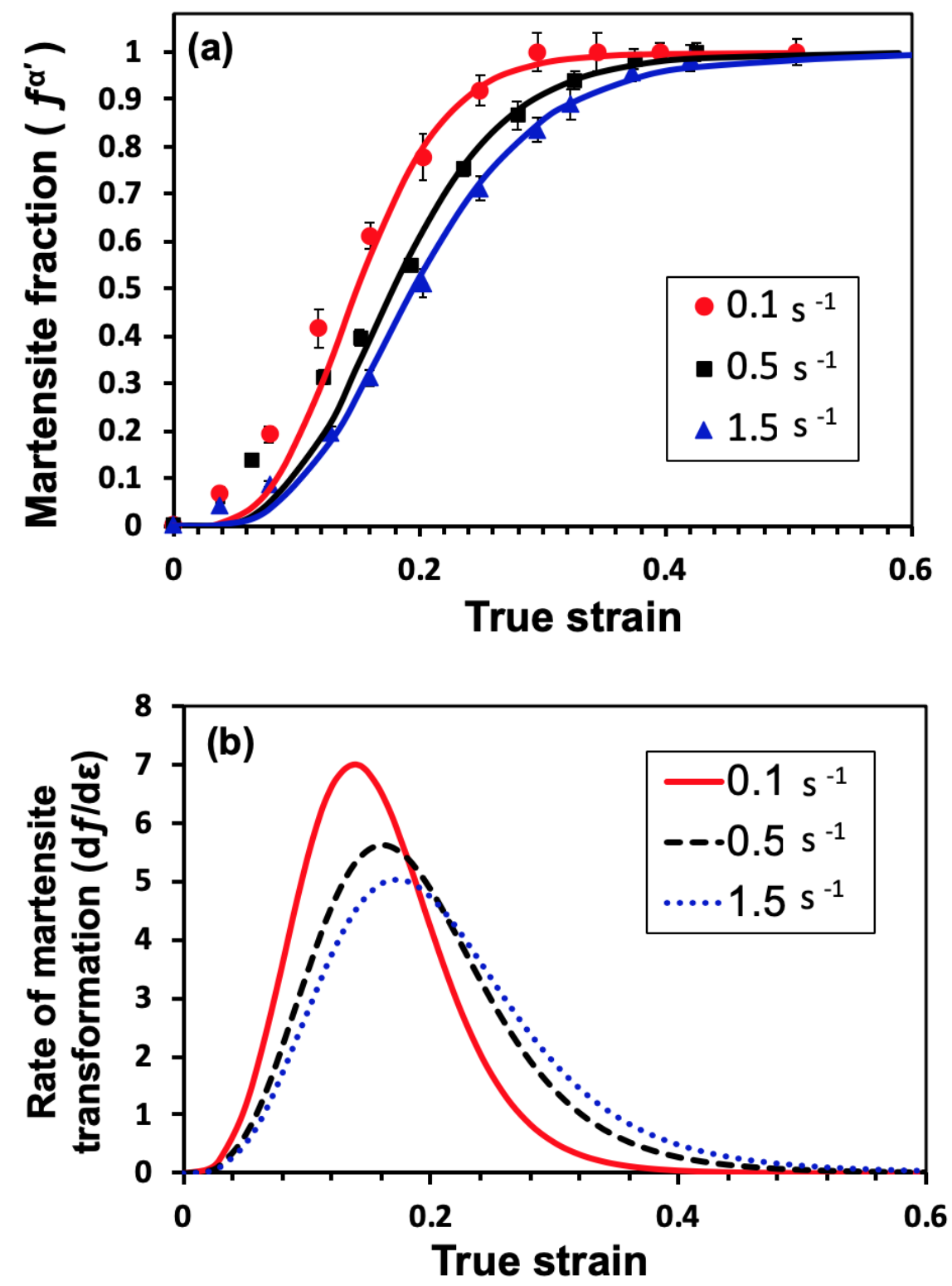

Figure 5. (a) Volume fraction of $\operatorname{SIM}\left(f^{\alpha^{\prime}}\right)$ as a function of true strain for Ti-bearing 201L steel at strain rates of $0.1,0.5$ and $1.5 \mathrm{~s}^{-1}$. (b) Corresponding curves of the rate of martensite transformation $\left(\mathrm{d} f^{\alpha^{\prime}} / \mathrm{d} \varepsilon\right)$ as a function of true strain.

It has been shown [6] that depending on the steel composition and deformation temperature, the shear bands are created in the deformed microstructures only beyond a certain stress level. At low stresses and strains, no shear bands could be observed. Accordingly, when the stress and strain increase, parallel shear bands appear in some grains. The density of the shear bands in the austenite increases with increasing stress and strain, and at higher strains stresses and strains, a shear band intersection also appears. Given that at $0.05 \mathrm{~mm}$ pass reduction the strain and stress level is gradually raised, it seems probable for the number of shear bands to be low at the earlier stages of deformation. 


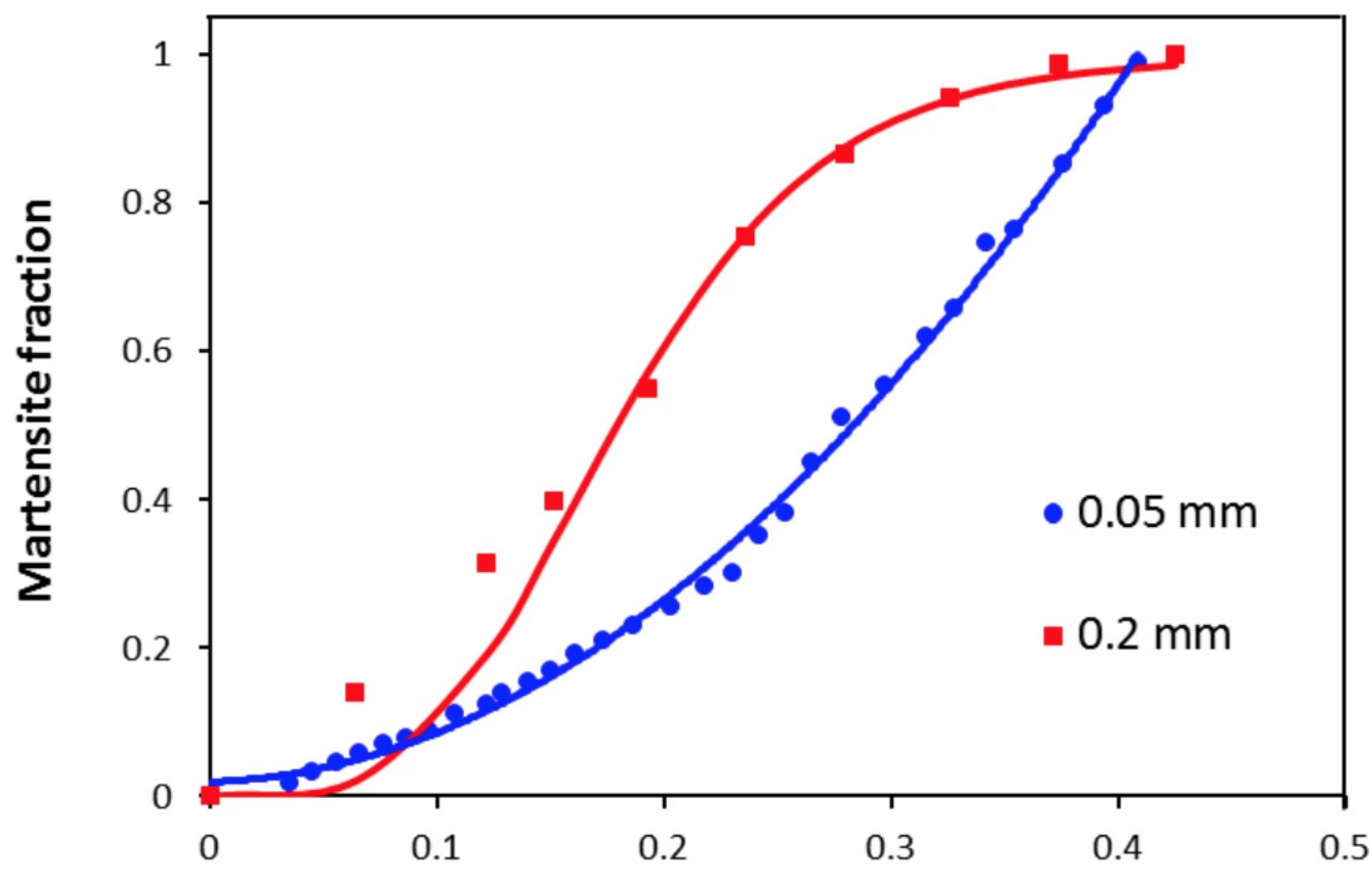

True Strain

Figure 6. The influence of pass reduction on the variation of SIM during the cold rolling of Ti-bearing 201L steel.

Further reductions produce parallel shear bands, and finally after a critical strain level, numerous intersections form between them, which enhances the martensite fraction significantly. However, this is a theoretical hypothesis, and supplementary experiments such as transmission electron microscopy could be employed to confirm or even reveal some other aspects and provide a better understanding of the mechanism. It is worth mentioning that there is a discrepancy between the experimental values and the fitted curves at low strain levels, as can be observed in Figures 3a, 5a and 6. This discrepancy in the beginning of the curves-which has also been observed in several other cases, in $[15,16]$, for example-suggests that the Olson and Cohen model does not fit perfectly for strains below 15\%. Maybe the inhomogeneous dispersion of SIM at low stain level affects the ferritescope and XRD measurements which are actually local measurements. But with increasing the applied strain which makes the dispersion of SIM more uniform, the discrepancy decreases, and the model fits very well. It is interesting that no discrepancy was observed for the thickness reduction of $0.05 \mathrm{~mm}$ per pass, though the fitted curve is different in that case. This can be attributed to the low strain level per pass and insignificant stress concentration resulting in more homogenous dispersion of SIM.

Figure 7 shows the influence of cold rolling reduction on the Vickers hardness for steel studied here along with the literature reference 201L [15] and 304L [16] steels. The cold rolling of the steels results in significant hardening and the most pronounced strain hardening occurs at relatively small thickness reductions. It is interesting to note that three stages (I, II and III) in all the plots can be determined. In stage I, the hardness variation is faster due to progressive formation of SIM as a hard phase during deformation. In this stage the hardness change of 304L is higher than that of the 201L steel; in spite that the rate of martensite formation is quite different between the two (Figure 3). The difference in the work hardening of $304 \mathrm{~L}$ and $201 \mathrm{~L}$ steels is ascribed to the difference in martensite hardness, which is related to the difference in the chemical composition. Stage II is a region of gradual increase or almost a plateau. Takaki et al. [32] have reported that some crystallographic distortions happen during cold rolling due to formation of slip bands in the martensite matrix. resulting in a change in the morphology of SIM from lath-type to dislocation-cell-type. Additionally, based on selected area electron 
diffraction analysis, Misra et al. [33] reported a transition of cold-rolled martensite structure from lath-type to dislocation-cell-type. They have emphasized that before dislocation-cell-type martensite is obtained, the sizes of martensite laths and packets decrease as a result of the breakup and destruction of martensite laths with increasing cold deformation. Apparently, the gradual increasing behavior in stage II probably corresponds to the mentioned transition. At this stage a high percentage of cold deformation is devoted to breaking the lath structure up into smaller laths. Meanwhile, the transformation rate during the stage II is lower than that of the stage I (according to Figure 3b). It can be concluded that low work hardening in the stage II arises from transition and destruction of lath structure. Stage III shows an intermediate work hardening in comparison with stages I and II. It can be assumed that the structure in stage III is fully dislocation-cell-type martensite. In this stage, further cold reduction leads to an increase in dislocation density within the martensite matrix and consequently work hardening. However, since the strength of martensite phase is much higher than austenite, the $\alpha^{\prime}$ phase is slightly deformed during cold rolling. Hence, the dislocation density in the dislocation-cell-type martensite which is nearly saturated, increases slowly.

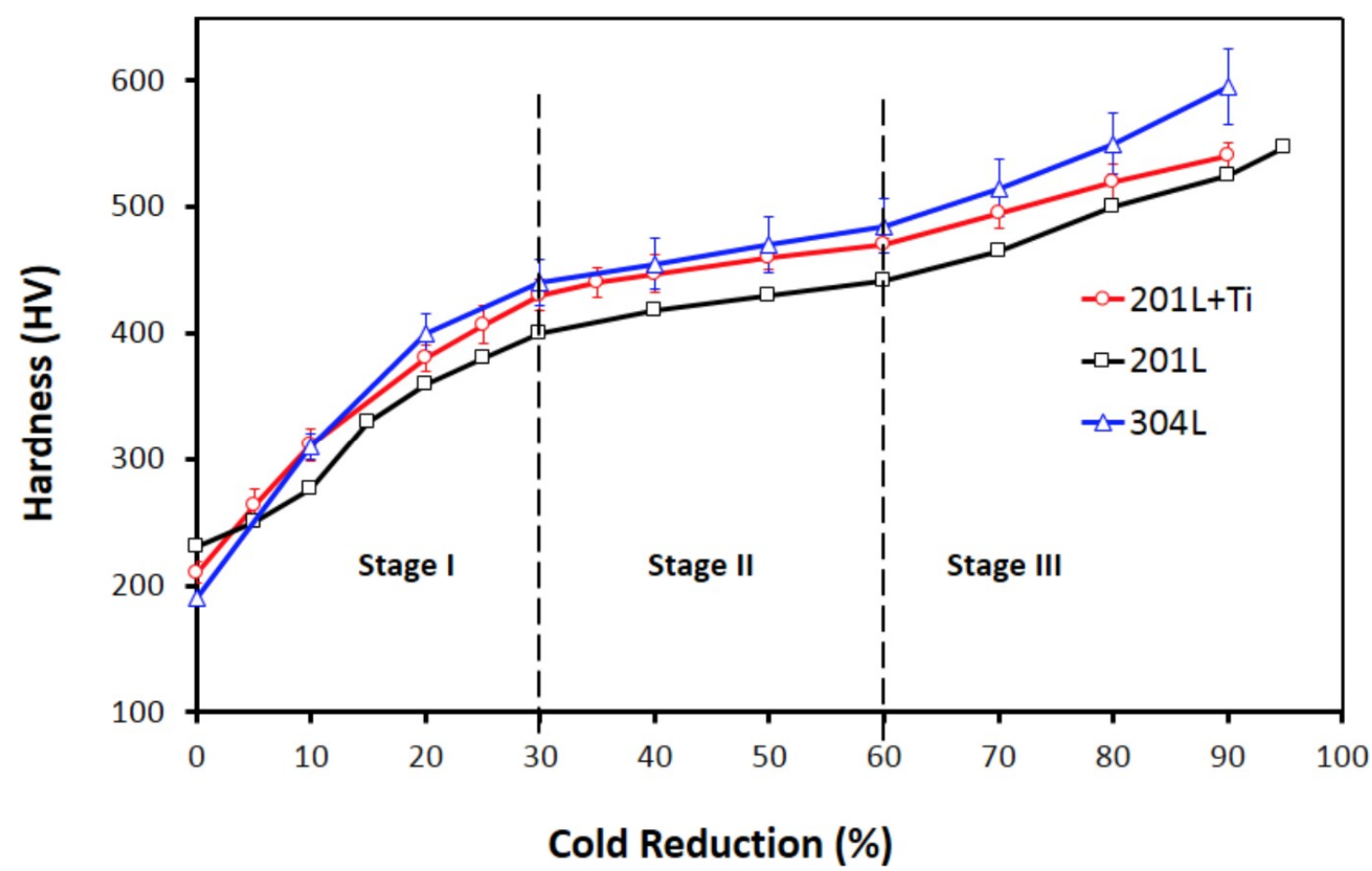

Figure 7. Hardness variation versus cold reduction percent for 304L, 201L and 201L + Ti steels.

It should be remarked that the microstructural evolution during deformation is a continuous process so that these stages during hardening may have some overlaps. An interesting feature to note is that, for the three steels, the onset points of stages II and III occurred at $~ 30 \%$ and $\sim 60 \%$ thickness reduction, respectively. This concept that is consistent with other observations elsewhere [26], which suggests that transition of martensite structure is not as dependent on chemical composition as the SFE. However, the exact locations of the critical points in the plots are difficult to define because of limited numbers of data points. Finally, the evolution of microstructure during cold rolling of ASSs at room temperature is summarized by schematic illustrations in Figure 8. 
a

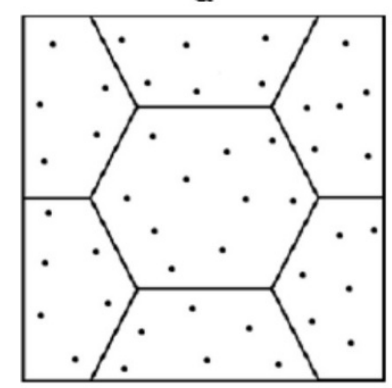

b

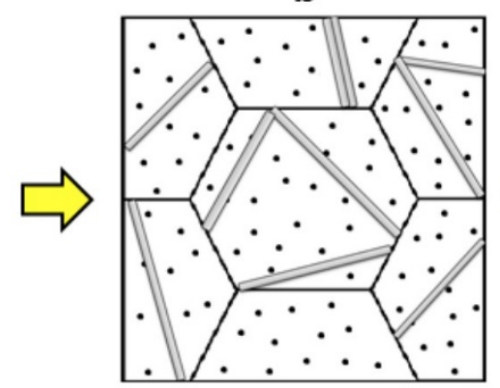

C

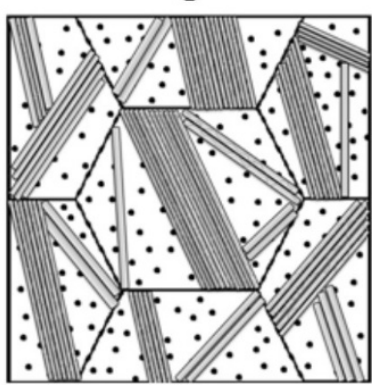

d
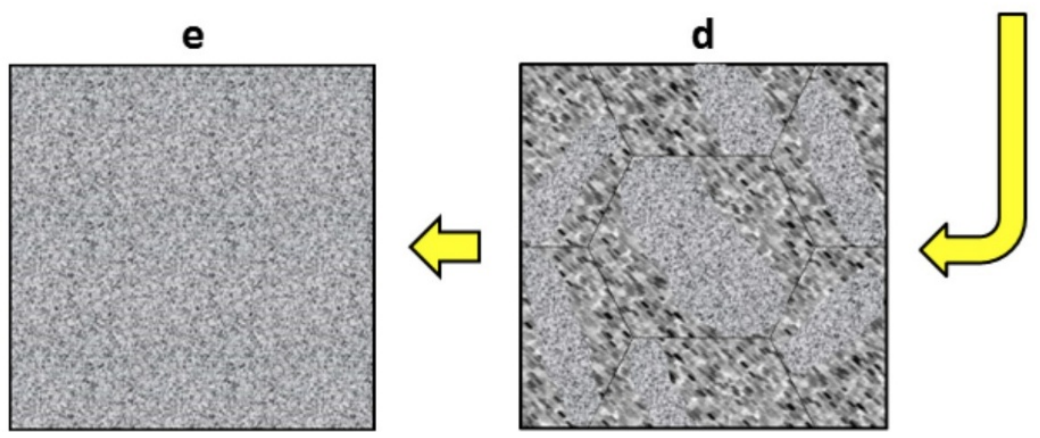

Figure 8. Schematic illustration of microstructural evolution during cold deformation of ASSs through the sequence of (a) initial equiaxed austenite grains, (b) an increase in dislocation density in $\gamma$ phase and the initiation of SIM formation, (c) decrease in lath width and packet size of SIM, (d) transition of lath-type martensite to dislocation-cell-type martensite simultaneous with increase in dislocation density and formation of fresh SIM and (e) spreading of dislocation-cell-type martensite.

The initial structure consists of equiaxed austenite grains with a low dislocation density due to former solution annealing (Figure 8a). When increasing the cold reduction in the initial stage, dislocation density in $\gamma$ phase and volume fraction of SIM increases, as shown in Figure $8 b$. With further increase in thickness reduction and at the beginning of stage II, the average lath width of $\alpha^{\prime}$-martensite and packet size decrease (Figure 8c). As a consequence, distortion takes place during deformation and breaks martensite packets up into smaller ones (Figure 8d). At this stage, the dislocation density in the $\gamma$ phase increases until a saturation limit and subsequently transforms to $\alpha^{\prime}$-martensite simultaneous with the transition of primary lath-type martensite to dislocation-cell-type martensite. Therefore, dislocation-cell-type martensite is observed predominantly at the end of stage II (Figure 8e). Over the stage III, further reductions deform the dislocation-cell-type martensite itself.

\section{Conclusions}

The effects of Ti addition, strain rate and strain increments on the kinetics of SIM formation in a high Mn stainless steel were evaluated and the following conclusions could be drawn:

- The austenitic structure of Ti-bearing 201L stainless steel is transformed to $\alpha^{\prime}$ martensite following the $\gamma \rightarrow \varepsilon \rightarrow \alpha^{\prime}$ sequence.

- Ti addition was found to have a promoting effect on the formation of SIM during cold rolling because of its reducing effect on the SFE.

- The kinetics of SIM formation are suppressed with increasing the strain rate due to adiabatic heating.

- Decreasing the pass reduction strongly changed variation of martensite volume fraction but did not show any influence on the martensite saturation strain $\left(\varepsilon_{\mathrm{s}}\right)$.

- A close correlation was found between the three stages of hardness variation and formation of $\alpha^{\prime}$-martensite and its microstructural evolution during cold rolling. 
Author Contributions: Conceptualization, S.S. and A.K.; Methodology, S.S. and A.K.; Investigation, S.S., V.J. and A.K.; Visualization, S.S. and V.J.; Writing—original draft, S.S.; Thermodynamic Calculation, V.J.; Writing-review \& editing, V.J., A.K. and J.K.; Supervision, A.K. and J.K. All authors have read and agreed to the published version of the manuscript.

Funding: This research was funded by Academy of Finland, grant number 311934.

Acknowledgments: The authors are grateful for financial support from Academy of Finland (\#311934—Genome of Steel Project). Vahid Javaheri would also like to thank the Jenny and Antti Wihuri Foundation for awarding a personal grant.

Conflicts of Interest: The authors declare no conflict of interest.

\section{References}

1. Spencer, K.; Embury, J.; Conlon, K.; Veron, M.; Brechet, Y. Strengthening via the formation of strain-induced martensite in stainless steels. Mater. Sci. Eng. A 2004, 387, 873-881. [CrossRef]

2. Das, A.; Sivaprasad, S.; Ghosh, M.; Chakraborti, P.; Tarafder, S. Morphologies and characteristics of deformation induced martensite during tensile deformation of $304 \mathrm{LN}$ stainless steel. Mater. Sci. Eng. A 2008, 486, 283-286. [CrossRef]

3. Murr, L.; Staudhammer, K.P.; Hecker, S.S. Effects of Strain State and Strain Rate on Deformation-Induced Transformation in 304 Stainless Steel: Part II. Microstructural Study. Met. Mater. Trans. A 1982, 13, $627-635$. [CrossRef]

4. $\quad$ Spencer, K.; Véron, M.; Yu-Zhang, K.; Embury, J.D. The strain induced martensite transformation in austenitic stainless steels: Part 1-Influence of temperature and strain history. Mater. Sci. Technol. 2009, 25, 7-17. [CrossRef]

5. Diani, J.M.; Parks, D.M. Effects of strain state on the kinetics of strain-induced marten- site in steels. J. Mech. Phys. Solids 1998, 46, 1613-1635. [CrossRef]

6. Talonen, J.; Hänninen, H. Formation of shear bands and strain-induced martensite during plastic deformation of metastable austenitic stainless steels. Acta Mater. 2007, 55, 6108-6118. [CrossRef]

7. Ferreira, P.; Müllner, P. A thermodynamic model for the stacking-fault energy. Acta Mater. 1998, 46, 4479-4484. [CrossRef]

8. Schramm, R.E.; Reed, R.P. Stacking fault energies of seven commercial austenitic stainless steels. Met. Mater. Trans. A 1975, 6, 1345-1351. [CrossRef]

9. Latanision, R.M.; Ruff, A.W. The temperature dependence of stacking fault energy in Fe-Cr-Ni alloys. Met. Mater. Trans. A 1971, 2, 505-509. [CrossRef]

10. Oshima, T.; Habara, Y.; Kuroda, K. Efforts to Save Nickel in Austenitic Stainless Steels. ISIJ Int. 2007, 47, 359-364. [CrossRef]

11. Hamada, A.; Karjalainen, L.; Misra, R.; Talonen, J. Contribution of deformation mechanisms to strength and ductility in two Cr-Mn grade austenitic stainless steels. Mater. Sci. Eng. A 2013, 559, 336-344. [CrossRef]

12. Tavares, S.S.M.; Pardal, J.; Da Silva, M.J.G.; Abreu, H.; Da Silva, M. Deformation induced martensitic transformation in a 201 modified austenitic stainless steel. Mater. Charact. 2009, 60, 907-911. [CrossRef]

13. Rezaee, A.; Kermanpur, A.; Najafizadeh, A.; Moallemi, M.; Baghbadorani, H.S. Investigation of cold rolling variables on the formation of strain-induced martensite in 201L stainless steel. Mater. Des. 2013, 46, 49-53. [CrossRef]

14. Seemann, P.; Kurz, S.; Gümpel, P. Martensite formation in a new manganese alloyed metastable austenitic steel (AISI 200-series). J. Alloy. Compd. 2013, 577, S649-S653. [CrossRef]

15. Rezaee, A.; Kermanpur, A.; Najafizadeh, A.; Moallemi, M. Production of nano/ultrafine grained AISI 201L stainless steel through advanced thermo-mechanical treatment. Mater. Sci. Eng. A 2011, 528, 5025-5029. [CrossRef]

16. Hedayati, A.; Najafizadeh, A.; Kermanpur, A.; Forouzan, F. The effect of cold rolling regime on microstructure and mechanical properties of AISI 304L stainless steel. J. Mater. Process. Technol. 2010, 210, 1017-1022. [CrossRef]

17. Talonen, J.; Aspegren, P.; Hänninen, H. Comparison of different methods for measuring strain induced $\alpha$-martensite content in austenitic steels. Mater. Sci. Technol. 2004, 20, 1506-1512. [CrossRef] 
18. Kruml, T.; Polák, J.; Degallaix, S. Microstructure in 316LN stainless steel fatigued at low tem- perature. Mater. Sci. Eng. A 2000, 293, 275-280. [CrossRef]

19. Humbert, M.; Petit, B.; Bolle, B.; Gey, N. Analysis of the $\gamma-\varepsilon-\alpha^{\prime}$ variant selection induced by $10 \%$ plastic deformation in 304 stainless steel at $-60^{\circ}$ C. Mater. Sci. Eng. A 2007, 454, 508-517. [CrossRef]

20. Olson, G.B.; Cohen, M. Kinetics of strain-induced martensitic nucleation. Met. Mater. Trans. A 1975, 6, 791-795. [CrossRef]

21. Herrera, C.; Ponge, D.; Raabe, D. Design of a novel Mn-based 1GPa duplex stainless TRIP steel with $60 \%$ ductility by a reduction of austenite stability. Acta Mater. 2011, 59, 4653-4664. [CrossRef]

22. Zaefferer, S.; Ohlert, J.; Bleck, W. A study of microstructure, transformation mechanisms and correlation between microstructure and mechanical properties of a low alloyed TRIP steel. Acta Mater. 2004, 52, 2765-2778. [CrossRef]

23. Forouzan, F.; Najafizadeh, A.; Kermanpur, A.; Hedayati, A.; Surkialiabad, R. Production of nano/submicron grained AISI 304L stainless steel through the martensite reversion process. Mater. Sci. Eng. A 2010, 527, 7334-7339. [CrossRef]

24. Eskandari, M.; Kermanpur, A.; Najafizadeh, A. Formation of nano-grained structure in a 301 stainless steel using a repetitive thermo-mechanical treatment. Mater. Lett. 2009, 63, 1442-1444. [CrossRef]

25. Padilha, A.F.; Plaut, R.; Rios, P.R. Annealing of Cold-worked Austenitic Stainless Steels. ISIJ Int. 2003, 43, 135-143. [CrossRef]

26. Talonen, J. Effect of Strain-Induced $\alpha^{\prime}$-Martensite Transformation on Mechanical Properties of Metastable Austenitic Stainless Steels; Helsinki University of Technilogy: Helsinki, Finland, 2007.

27. Ferreira, P.J.; Sande, J.B.V.; Fortes, M.A.; Kyröläinen, A. Microstructure development during high-velocity deformation. Met. Mater. Trans. A 2004, 35, 3091-3101. [CrossRef]

28. Hecker, S.S.; Stout, M.G.; Staudhammer, K.P.; Smith, J.L. Effects of Strain State and Strain Rate on Deformation-Induced Transformation in 304 Stainless Steel: Part I. Magnetic Measurements and Mechanical Behavior. Met. Mater. Trans. A 1982, 13, 619-626. [CrossRef]

29. Talonen, J.; Hänninen, H.; Nenonen, P.; Pape, G. Effect of strain rate on the strain-induced $\gamma \rightarrow \alpha^{\prime}$-martensite transformation and mechanical properties of austenitic stainless steels. Metall. Mater. Trans. A 2005, 36, 421-432. [CrossRef]

30. Stauffer, D.; Aharony, A. Introduction to Percolation Theory; CRC: Boca Raton, FL, USA, 1994.

31. Somani, M.C.; Juntunen, P.; Karjalainen, L.P.; Misra, R.D.K.; Kyröläinen, A. Enhanced Mechanical Properties through Reversion in Metastable Austenitic Stainless Steels. Metallur- Gical Mater. Trans. A 2009, 40, 729-744. [CrossRef]

32. Takaki, S.; Tomimura, K.; Ueda, S. Effect of Pre-cold-working on Diffusional Reversion of Deformation Induced Martensite in Metastable Austenitic Stainless Steel. ISIJ Int. 1994, 34, 522-527. [CrossRef]

33. Misra, R.; Nayak, S.; Mali, S.; Shah, J.; Somani, M.; Karjalainen, L. On the Significance of Nature of Strain-Induced Martensite on Phase-Reversion-Induced Nanograined/Ultrafine-Grained Austenitic Stainless Steel. Met. Mater. Trans. A 2009, 41,3-12. [CrossRef]

(C) 2020 by the authors. Licensee MDPI, Basel, Switzerland. This article is an open access article distributed under the terms and conditions of the Creative Commons Attribution (CC BY) license (http://creativecommons.org/licenses/by/4.0/). 